\title{
Gross Motor Function Classification System Expanded \& Revised (GMFCS E \& R): reliability between therapists and parents in Brazil
}

\author{
Daniela B. R. Silva, Luzia I. Pfeifer, Carolina A. R. Funayama
}

\begin{abstract}
Background: Several studies have demonstrated the importance of using the Gross Motor Function Classification System (GMFCS) to classify gross motor function in children with cerebral palsy, but the reliability of the expanded and revised version has not been examined in Brazil (GMFCS E \& R). Objective: To determine the intraand inter-rater reliability of the Portuguese-Brazil version of the GMFCS E \& R applied by therapists and compare to classification provided by parents of children with cerebral palsy. Method: Data were obtained from 90 children with cerebral palsy, aged 4 to 18 years old, attending the neurology or rehabilitation service of a Brazilian hospital. Therapists classified the children's motor function using the GMFCS E \& R and parents used the Brazilian Portuguese version of the GMFCS Family Report Questionnaire. Intra- and inter-rater reliability was obtained through percentage agreement and Cohen's unweighted Kappa statistics (k). The Chi-square test was used to identify significant differences in the classification of parents and therapists. Results: Almost perfect agreement was reached between the therapists $[\mathrm{K}=0.90$ (95\% confidence interval 0.83-0.97)] and intra-raters (therapists) with $\mathrm{K}=1.00$ [95\% confidence interval (1.00-1.00)], $\mathrm{p}<0.001$. Agreement between therapists and parents was substantial $(\mathrm{k}=0.716$, confidence interval 0.596-0.836), though parents classify gross motor impairment more severely than therapists $(\mathrm{p}=0.04)$. Conclusions: The Portuguese version of the GMFCS E \& R is reliable for use by parents and therapists. Parents tend to classify their children's limitations more severely, because they know their performance in different environments.
\end{abstract}

Keywords: cerebral palsy; reliability; gross motor function; rehabilitation.

\section{HOW TO CITE THIS ARTICLE}

Silva DBR, Pfeifer LI, Funayama CAR. Gross Motor Function Classification System Expanded \& Revised (GMFCS E \& R): reliability between therapists and parents in Brazil. Braz J Phys Ther. 2013 Sept-Oct; 17(5):458-463. http://dx.doi.org/10.1590/ S1413-35552012005000113

\section{Introduction}

Cerebral Palsy $(\mathrm{CP})$ describes a group of permanent disorders of the development of movement and posture, causing activity limitation, that are attributed to nonprogressive disturbances that occurred in the developing fetal or infant brain. The motor disorders of cerebral palsy are often accompanied by disturbances of sensation, perception, cognition, communication, and behavior, by epilepsy, and by secondary musculoskeletal problems ${ }^{1}$. $\mathrm{CP}$ is divided into three groupings based on the predominat neuromotor abnormality: spastic (unilateral and bilateral), dyskinetic (dystonia and choreoathetosis) or ataxic ${ }^{1}$.

However, the functional consequences of involvement of the upper and lower extremities should therefore be separately classified using objective functional scales ${ }^{1}$ as the Gross Motor Function Classification System (GMFCS) ${ }^{2}$.The GMFCS was developed in response to the need to have a standardized system for describing and classifying the severity of movement disability among children with cerebral palsy. The GMFCS is a 5 level classification system on the basis of their self-initiated movement with particular emphasis on sitting, walking, and wheeled mobility. Level I includes children and youth with $\mathrm{CP}$ who walk without limitations, and Level II includes limitations walking long distances and balancing. In Level III, the individual walks using a hand-held mobility device (canes, crutches, walkers). Children and youth in level IV are more likely to be transported in a manual wheelchair or use powered mobility. In Level V, individuals have severe limitations in head and trunk control and require extensive assisted technology and physical assistance ${ }^{2}$. The GMFCS includes four age bands (less than 2 years, 2 to 4 years, 4 to 6 years, and 6 to 12 years $)^{2}$ and it is cross-culturally adapted to Brazilian Portuguese ${ }^{3}$. 
The GMFCS Expanded and Revised ${ }^{4}$ (GMFCS E \& R) includes age band for youth 12-18 years of age and its translation into the Portuguese language (Brazil) was conducted in 2010 by a group that included a neurologist and occupational therapists. The translation procedure was applied according to the guidelines of Canchild - Centre For Childhood Disability research website and the Portuguese version (Brazil) of GMFCS E \& $\mathrm{R}$ form can be downloaded from this website (http://www.canchild. ca). The validity and reliability of the original GMFCS have been studied extensively and are well established $^{2,5,6}$, and the reliability of the expanded version of the GMFCS has been examined in Canada ${ }^{4}$ and Turkey ${ }^{7}$.

The classification system is widely used among healthcare professionals to establish goals, give prognoses, and make decisions ${ }^{1,8}$. The GMFCS Family Report Questionnaire ${ }^{9}$ has been used by parents of children with $\mathrm{CP}$ to classify gross motor function and has been shown to be consistent with those of health professionals in studies conducted in both Canada ${ }^{9}$ and the UK ${ }^{10,11}$. Such classification may differ due to children's varying performance in relation to methods of mobility ${ }^{12}$ in different environments (home, school, hospital). Families will almost certainly know their children's ability across a broader range of settings ${ }^{11}$. However, it is important to determine the level of agreement between healthcare professionals and parents when classifying a child with $\mathrm{CP}$ using versions of the GMFCS ${ }^{13}$.

The aims of the present study were: (1) to determine the inter-rater and intra-rater reliability of the Portuguese version of the GMFCS E \& R; (2) to examine reliability of parent report using the GMFCS Family Report Questionnaire in children with cerebral palsy aged 4 to 12 years in comparison with therapists; and (3) to find significant differences between the perception of parents and therapists in relation to children's motor limitation using the GMFCS E \& R.

\section{- Method}

This cross-sectional, non-experimental quantitative study was conducted to compare the classification of the gross motor function of individuals with $\mathrm{CP}$ according to parents and therapists. The study was approved by the Research Ethics Committee at Hospital das Clínicas at Faculdade de Medicina de Ribeirão Preto, Universidade de São Paulo (FMRPUSP), Ribeirão Preto, SP, Brazil. The parents provided written consent (HCRP no. 12469/2008).

\section{Participants}

For the assessment of inter-rater reliability, 90 individuals with CP participated, aged between 4 and 18 years old. For the assessment of reliability between therapists and parents, only 84 parents and their children with $\mathrm{CP}$ attended. Six youths between 12 and 18 years were excluded, since the GMFCS Family Report Questionnaire did not encompass this age at the time of data collection.

The participating children attended the Occupational Therapy Service and/or the Physical Therapy Service at the Rehabilitation Center or the Neurology service of Hospital das Clínicas of FMRPUSP between September 2010 and October 2011.

A convenience sample was used and the inclusion criteria were: having a diagnosis of $\mathrm{CP}$ regardless of the type or severity of motor impairment and being 4 to 18 years old. Exclusion criteria were children who were deaf or blind, who did not perform visual fixation or had epilepsy.

\section{Data collection procedure}

Two occupational therapists collected data simultaneously from separate places. The first evaluator (E1) remained with the parent or guardian, and the second evaluator (E2) remained with the child. E1 has nine years of professional experience in the rehabilitation of children with $\mathrm{CP}$ and is familiar with the GMFCS. E2 is an Occupational Therapy undergraduate and is not very familiar with the classification system. A research assistant collaborated in the study as a third occupational therapist (Evaluator 3 - E3) responsible for filming and selecting the videos for retest.

From the parents, E1 collected information concerning the children's age and the parents' education, profession, income, and age. The Brazilian Portuguese version of the GMFCS Family Report Questionnaire (available at http://www.canchild.ca) was read to the parents so they could identify a single motor level. The parents were instructed to choose the closest level to the child's motor skill.

E2 observed the children in relation to trunk control, gait, and transfers and classified them according to the Brazilian Portuguese version of the GMFCS E \& R (available at http://www.canchild.ca). This procedure was filmed by E3 and subsequently used for intra- and inter-rater analysis. Data about locomotion at school, outdoors, and in the community was obtained from the parents.

In order to include all levels of the GMFCS E \& $\mathrm{R}$, both evaluators (E1 and E2) watched 30 videos selected by E3 to assess intra-rater reliability. E2 
performed the first evaluation when the children were filmed, and E1 evaluated the children 2 weeks later to avoid memory bias (e.g., remembering the classification chosen by parents). The second evaluation (retest) took place one month after the first. Both E1 and E2 watched the videos again separately to classify the level of the children's motor impairment. The initial classifications performed by E1 (the occupational therapist with the most experience with children with $\mathrm{CP}$ ) were taken as a reference to compare the classifications performed by the therapists and parents.

\section{Statistical analysis}

The GMFCS E \& $\mathrm{R}$ is an ordinal scale with five levels. Descriptive statistics were used to characterize the participants. Ordinal data were analyzed using percentage agreement and Cohen's unweighted Kappa $(\mathrm{k})$ to examine parent-therapist agreement and intra- and inter-rater agreement.

The following characterizations were used for the Kappa coefficient: values below zero (poor), between 0.00 and 0.20 (negligible), between 0.21 and 0.40 (mild), between 0.41 and 0.60 (moderate), between 0.61 and 0.80 (substantial), and between 0.81 and 1.0 (almost perfect agreement) ${ }^{14}$. The Chi-square test was used to find significant differences between the perception of parents and therapists in relation to motor limitation of child using the GMFCS E\&R.

\section{Results}

The average age of children was 7.58 years (7 years and 7 months), ranging from 4 to 17.91 years old. Most were classified as children with spastic bilateral cerebral palsy $(n=61)$, unilateral spastic $(n=17)$, dyskinetic $(n=9)$, and ataxic $(n=3) C P$. Regarding sex, the sample was equally distributed.

The children with unilateral CP were frequently classified by the occupational therapist (E1) as levels I and II of the GMFCS E \& R $(82.4 \%$ in level I and $17.6 \%$ in level II). Most of those with bilateral CP were classified as level IV (27.9\%), although the gross motor function of these children was distributed over the GMFCS E \& R levels (Table 1). In relation to the parents, only one questionnaire (GMFCS Family Report Questionnaire) was answered by a father; all the remaining were answered by mothers, the primary caregiver. The children's characteristics and those of the parents are described in Table 1.

\section{Inter-rater evaluation}

Table 2 presents the results of inter-rater agreement, considered to be almost perfect ( $\mathrm{k}=0.90$, confidence interval [CI] 0.83-0.97), with 7 disagreements out of a total of 90 children.

The table shows a high rate of agreement in all levels, with most disagreements (4 out of 7) found levels IV and V.

\section{Intra-rater evaluation}

One month after their initial evaluation, the evaluators (E1 and E2) repeated the classification of the gross motor function of the 30 children with $\mathrm{CP}$ (retest). Both evaluators obtained a near perfect intrarater agreement $(\mathrm{k}=1.00$, confidence interval $[\mathrm{CI}]$ $1.00-1.00, \mathrm{p}<0.001)$, i.e. there was no disagreement between the classifications performed at different points in time.

Table 1. Characteristics of children and their caregivers (obtained by the E 1).

\begin{tabular}{|c|c|c|c|c|c|c|}
\hline CP type & Level I & Level II & Level III & Level IV & Level V & Total \\
\hline Bilateral spastic & 6 & 12 & 14 & 17 & 12 & 61 \\
\hline Unilateral spastic & 14 & 3 & - & - & - & 17 \\
\hline Dyskinetic & - & 2 & - & 3 & 4 & 9 \\
\hline Ataxic & 1 & 1 & - & 1 & - & 3 \\
\hline Caregivers' characteristics & Average & Standard deviation & Minimum & Maximum & & \\
\hline Age & 34.06 & 8.777 & 19 & 56 & & \\
\hline Years of schooling & 8.80 & 3.299 & 0 & 15 & & \\
\hline Income & $1,222.81$ & 787.347 & 250.00 & 6,000 & & \\
\hline Occupation & (n) & & & & & \\
\hline Does not work & 62 & & & & & \\
\hline Works & 28 & & & & & \\
\hline
\end{tabular}


Table 2. Classifications performed by evaluators 1 and 2 (occupational therapists) based on the GMFCS E \& R.

\begin{tabular}{ccccccc}
\hline & \multicolumn{5}{c}{ Evaluator 2 } \\
Evaluator 1 & Level I & Level II & Level III & Level IV & Level V & Total \\
Level I & 19 & 1 & - & - & - & 20 \\
Level II & - & 18 & - & - & - & 18 \\
Level III & - & - & 13 & 1 & - & 14 \\
Level IV & - & - & 1 & 17 & 3 & 21 \\
Level V & - & - & - & 1 & 16 & 17 \\
Total & 19 & 19 & 14 & 19 & 19 & 90 \\
\hline
\end{tabular}

Table 3. Classifications performed by evaluator 1 and parents according to the GMFCS E \& R.

\begin{tabular}{ccccccc}
\hline & \multicolumn{5}{c}{ GMFCS parents } \\
Evaluator 1 & Level I & Level II & Level III & Level IV & Level V & Total \\
Level I & 15 & 3 & - & - & - & 18 \\
Level II & - & 17 & - & - & - & 17 \\
Level III & - & 1 & 8 & 2 & 1 & 12 \\
Level IV & - & - & 1 & 11 & 8 & 20 \\
Level V & - & - & - & 3 & 14 & 17 \\
Total & 15 & 21 & 9 & 16 & 23 & 84 \\
\hline
\end{tabular}

\section{Reliability between therapists and parents}

Substantial agreement was observed between the classification performed by the therapist (E1) and that performed by parents $(\mathrm{k}=0.71$, confidence interval [CI] 0.59-0.83, $\mathrm{p}<0.001$ ). Table 3 presents the classifications according to the GMFCS E \& R of both $\mathrm{E} 1$ and the parents.

There were 19 discrepancies between the ratings of parents and therapists. There were three disagreements between levels I and II, one between levels II and III, three between III and IV, and 11 between levels IV and V. Furthermore, there was a discrepancy between levels III and V when the therapist classified the child in level III and the parents in level V.

Even though substantial agreement was reached between parents and therapists, a total of 19 cases of disagreement were observed. In $5(26.3 \%)$ of these, the parents classified the children in levels below those classified by the therapist, indicating lower motor impairment (26.3\%). In the 14 (73.7\%) remaining cases, the parents classified the children at higher levels of motor impairment, showing significant difference according to the Chi-square test $(\mathrm{p}=0.04)$.

\section{Discussion}

The Gross Motor Function Classification System has been widely used in research and clinical practice, being a valid and reliable instrument to evaluate the gross motor function of children with cerebral palsy ${ }^{2,5}$. The results indicated near perfect agreement between the health professionals with different levels of experience with children with $\mathrm{CP}$ aged 4 to 18 years and classified by the Brazilian Portuguese version of the GMFCS E \& R. The intrarater agreement obtained in this study was higher than that reported in the initial study on GMFCS involving children aged 0 to 12 years and therapists who were familiar with the children $(\mathrm{k}=0.75)^{2}$. However, our sample did not include children younger than 4 years because the inter-rater reliability for children under 2 years has been shown to be lower given the tendency of these children to be reclassified at lower levels (less functional limitation). In older children, however, there is greater stability of functional abilities ${ }^{13}$.

McDowell et al. ${ }^{10}$ found substantial agreement between two physical therapists, one familiar and the other unfamiliar with the children included in the study $(\mathrm{k}=0.64)$. Excellent agreement was obtained in the present study even though neither of the evaluators (E1 and E2) in this study were 
familiar with the children. Such a result was different from that found by Morris et al. ${ }^{11}$, who obtained much lower values. Kappa was equal to 0.65 when the classification was performed by physical therapists and pediatricians, and equal to 0.38 when the classification was performed by orthopedic surgeons and physical therapists and then between orthopedic surgeons and pediatricians. Classification in these cases could be based on direct observation, medical files or both. Kappa was equal to $0.67^{15}$ when the reliability among clinicians was verified and classification was based on medical files. The results concerning reliability differ depending on the different health professionals performing the classifications and on the methods used to collect information, but, in general, the GMFCS is very reliable for classifying the gross motor function of children with CP.

The classification in this study was repeated by the occupational therapists one month later, when near perfect agreement was reached between the evaluators. Few studies have evaluated intra-rater reliability performed by healthcare professionals. The study conducted by Gainsborough et al. ${ }^{16}$, which included 20 respondents who repeated the classification of 10 children using the GMFCS after 5 months through the study of written cases, obtained a Kappa equal to 0.72 .

Substantial agreement was obtained between occupational therapists and parents and disagreement predominated in levels IV and V, unlike other studies $^{2,9,17}$, in which disagreement was found in levels I and II (no walking aids). The children classified as levels IV and V require the use of assistive technology (manual or powered wheelchair), which depends on contextual factors ${ }^{12}$ such as accessibility to these resources, architectural barriers, as well as personal factors including acceptance of colleagues and family ${ }^{12}$. The cost of a wheelchair in Brazil is high, however, the Brazilian government has increased funding for the Health System to provide free wheelchairs at national, state, and municipal levels ${ }^{18}$

Additionally, caregivers tend to classify children's motor impairment more severely than therapists ${ }^{9-11,13}$. Parents interact with children in different environments and situations while healthcare professionals generally evaluate children in a standardized environment such as a clinic or school ${ }^{9,13}$ and tend to overestimate the child's skills, that is, the child's maximum functional skill, minimizing any limiting effect of the environment ${ }^{13}$. There is great variability in the mobility of children with $\mathrm{CP}$, which depends on environmental and personal factors ${ }^{12}$. Most of the mothers in this study did not work outside the home, but rather spent the entire day with their children and knew the child's performance in each environment (home, school, community).

Partnerships between families and healthcare professionals need to be established in clinical practice to provide effective collaborative familycentered care. Healthcare professionals should recognize the parents as experts in identifying their children's needs and skills across a broader range of settings, while parents also need the opinions of therapists and physicians to help them make decisions when necessary ${ }^{11}$. Therefore, it is recommended that the classifications regarding the GMFCS E \& R are made independently by healthcare professionals and parents. In case of disagreements (which occur in a minority of cases) a consensus should be reached on a classification as a basis for making subsequent clinical decisions ${ }^{13}$.

Therefore, the Brazilian Portuguese version of the GMFCS E \& R has proven reliable for use by healthcare professionals with different levels of experience and parents. It can be easily incorporated into clinical practice to define the prognosis and treatment goals that may involve the need for assistive technology, and into research to compare similar groups ${ }^{6}$.

This study's limitations include the age range (between 4 and 12 years old) of the studied children. Future studies are necessary to address children 0 to 4 years old and adolescents 12 to 18 years old and also to evaluate the classification or parents at different points in time to verify test-retest reliability in comparison to healthcare professionals. Additionally, the reliability of the classification among different professionals (physical therapists, pediatricians, neurologists, orthopedists) should be verified in Brazil.

\section{References}

1. Rosenbaum P, Paneth N, Leviton A, Goldstein M, Bax M. A report: the definition and classification of cerebral palsy April 2006. Dev Med Child Neurol. 2007;49(Suppl.109):8-14. http://dx.doi. org/10.1111/j.1469-8749.2007.tb12610.x

2. Palisano RJ, Rosenbaum P, Walter S, Russell D, Wood E, Galuppi B. Development and reliability of a system to classify gross motor function in children with cerebral palsy. Dev Med Child Neurol. 1997;39(4):214-23. PMid:9183258. http://dx.doi.org/10.1111/j.1469-8749.1997.tb07414.x

3. Hiratuka E, Matsukura TS, Pfeifer LI. Cross-cultural adaptation of the Gross Motor Function Classification System into Brazilian-Portuguese (GMFCS). Rev Bras 
Fisioter 2010;14(6):537-44. http://dx.doi.org/10.1590/ S1413-35552010000600013

4. Palisano RJ, Rosenbaum P, Bartlett D, Livingston MH. Content validity of the expanded and revised Gross Motor Function Classification System. Dev Med Child Neurol. 2008;50(10):744-50. PMid:18834387. http:// dx.doi.org/10.1111/j.1469-8749.2008.03089.x

5. Palisano RJ, Hanna SE, Rosenbaum PL, Russell DJ, Walter SD, Wood EP, et al. Validation of a model of gross motor function for children with cerebral palsy. Phys Ther. 2000;80(10):974-85. PMid:11002433.

6. Wood E, Rosenbaum P. The Gross Motor Function Classification System for cerebral palsy: a study of reliability and stability over time. Dev Med Child Neurol. 2000;42(5):292-6. http://dx.doi.org/10.1017/ S0012162200000529

7. El Ö, Baydar M, Berk H, Peker Ö, Kosay C, Demiral Y. Interobserver reliability of the Turkish version of the expanded and revised gross motor function classification system. Disabil Rehabil. 2012;34(12):10303. PMid:22126744. http://dx.doi.org/10.3109/09638288. 2011.632466

8. Morris C, Bartlett D. Gross Motor Function Clasisfication System: impact and utility. Dev Med Child Neurol. 2004;46(1):60-5. PMid:14974650. http://dx.doi. org/10.1111/j.1469-8749.2004.tb00436.x

9. Morris C, Galuppi BE, Rosenbaum PL. Reliability of family report for the Gross Motor Function Classification System. Dev Med Child Neurol. 2004;46(7):455-60. PMid:15230458. http:// dx.doi.org/10.1111/j.1469-8749.2004.tb00505.x

10. McDowell BC, Kerr C, Parkes J. Interobserver agreement of the Gross Motor Function Classification System in an ambulant population of children with cerebral palsy. Dev Med Child Neurol. 2007;49(7):528-33. PMid:17593126. http://dx.doi.org/10.1111/j.1469-8749.2007.00528.x

11. Morris C, Kurinczuk JJ, Fitzpatrick R, Rosenbaum PL. Who best to make the assessment? Professional's and families' classifications of gross motor function in cerebral palsy are highly consistent. Arch Dis Child. 2006;91(8):675-9. PMid:16638783 PMCid:PMC2083065. http://dx.doi. org/10.1136/adc.2005.090597

12. Palisano RJ, Tieman BL, Walter SD, Bartlett DJ, Rosenbaum PL, Russell D, et al. Effect of environment setting on mobility methods of children with cerebral palsy. Dev Med Child Neurol. 2003;45(2):113-20. PMid:12578237. http://dx.doi.org/10.1111/j.1469-8749.2003.tb00914.x
13. Jewell AT, Stokes AI, Bartlett DJ. Correspondence of classifications between parents of children with cerebral palsy aged 2 to 6 years and therapists using the Gross Motor Function Classification System. Dev Med Child Neurol. 2011;53(4):334-7. PMid:21166672. http://dx.doi. org/10.1111/j.1469-8749.2010.03853.x

14. Landis JR, Koch GG. The measurements of observer agreement for categorical data. Biometrics. 1977;33:15974. http://dx.doi.org/10.2307/2529310

15. Benedict RE, Patz J, Maenner MJ, Arneson CL, Yeargin-Allsopp M, Doernberg NS, et al. Feasibility and reliability of classifying gross motor function among children with cerebral palsy using populationbased record surveillance. Paediatr Perinat Epidemiol. 2011;25(1):88-96. PMid:21133973. http:// dx.doi.org/10.1111/j.1365-3016.2010.01164.x

16. Gainsborough M, Surman G, Maestri G, Colver A, Cans C. Validity and reliability of the guidelines of the Surveillance of Cerebral Palsy in Europe for the classification of cerebral palsy. Dev Med Child Neurol. 2008;50(11):828-31. PMid:19058397. http:// dx.doi.org/10.1111/j.1469-8749.2008.03141.x

17. Kondo I, Hosokawa K, Soma M, Iwata M, Sato Y, Iwasaki M, et al. Gross Motor Function Classifcation System: Preliminary study for Japanese children. Am J Phys Med Rehabil. 2003;82(2):116-21. PMid:12544757. http:// dx.doi.org/10.1097/00002060-200302000-00006

18. Brasil. Ministério da Saúde. Portaria n ${ }^{\circ} 835$, de 25 de abril de 2012. Institui incentivos financeiros de investimento e de custeio para o componente atenção especializada da rede de cuidados à pessoa com deficiência no âmbito do sistema único de saúde. Diário Oficial da República Fedeartiva do Brasil, Brasília, 25 abr 2012.

\section{Correpondence}

\section{Daniela Baleroni Rodrigues Silva}

Universidade de São Paulo

Faculdade de Medicina de Ribeirão Preto

Divisão de Terapia Ocupacional

Departamento de Neurociências e Ciências do Comportamento Av. Bandeirantes, 3900, Hospital das Clínicas, $4^{\circ}$ andar CEP 14049-900, Ribeirão Preto, SP, Brasil

e-mail: dani_brs@fmrp.usp.br 